\title{
A NEW COMPOSITE IMPLICIT ITERATIVE PROCESS FOR A FINITE FAMILY OF NONEXPANSIVE MAPPINGS IN BANACH SPACES
}

FENG GU AND JING LU

Received 18 January 2006; Revised 22 August 2006; Accepted 23 August 2006

The purpose of this paper is to study the weak and strong convergence of implicit iteration process with errors to a common fixed point for a finite family of nonexpansive mappings in Banach spaces. The results presented in this paper extend and improve the corresponding results of Chang and Cho (2003), Xu and Ori (2001), and Zhou and Chang (2002).

Copyright (c) 2006 F. Gu and J. Lu. This is an open access article distributed under the Creative Commons Attribution License, which permits unrestricted use, distribution, and reproduction in any medium, provided the original work is properly cited.

\section{Introduction and preliminaries}

Throughout this paper we assume that $E$ is a real Banach space and $T: E \rightarrow E$ is a mapping. We denote by $F(T)$ and $D(T)$ the set of fixed points and the domain of $T$, respectively.

Recall that $E$ is said to satisfy Opial condition [11], if for each sequence $\left\{x_{n}\right\}$ in $E$, the condition that the sequence $x_{n} \rightarrow x$ weakly implies that

$$
\liminf _{n \rightarrow \infty}\left\|x_{n}-x\right\|<\liminf _{n \rightarrow \infty}\left\|x_{n}-y\right\|
$$

for all $y \in E$ with $y \neq x$. It is well known that (see, e.g., Dozo [9]) inequality (1.1) is equivalent to

$$
\limsup _{n \rightarrow \infty}\left\|x_{n}-x\right\|<\limsup _{n \rightarrow \infty}\left\|x_{n}-y\right\|
$$

Definition 1.1. Let $D$ be a closed subset of $E$ and let $T: D \rightarrow D$ be a mapping.

(1) $T$ is said to be demiclosed at the origin, if for each sequence $\left\{x_{n}\right\}$ in $D$, the conditions $x_{n} \rightarrow x_{0}$ weakly and $T x_{n} \rightarrow 0$ strongly imply $T x_{0}=0$. 
2 A new composite implicit iterative process

(2) $T$ is said to be semicompact, if for any bounded sequence $\left\{x_{n}\right\}$ in $D$ such that $\left\|x_{n}-T x_{n}\right\| \rightarrow 0(n \rightarrow \infty)$, then there exists a subsequence $\left\{x_{n_{i}}\right\} \subset\left\{x_{n}\right\}$ such that $x_{n_{i}} \rightarrow x^{*} \in D$.

(3) $T$ is said to be nonexpansive, if $\|T x-T y\| \leq\|x-y\|$, for all $n \geq 1$ for all $x, y \in D$.

Let $E$ be a Hilbet space, let $K$ be a nonempty closed convex subset of $E$, and let $\left\{T_{1}, T_{2}, \ldots, T_{N}\right\}: K \rightarrow K$ be $N$ nonexpansive mappings. In 2001, Xu and Ori [19] introduced the following implicit iteration process $\left\{x_{n}\right\}$ defined by

$$
x_{n}=\alpha_{n} x_{n-1}+\left(1-\alpha_{n}\right) T_{n(\bmod N)} x_{n}, \quad \forall n \geq 1,
$$

where $x_{0} \in K$ is an initial point, $\left\{\alpha_{n}\right\}_{n \geq 1}$ is a real sequence in $(0,1)$ and proved the weakly convergence of the sequence $\left\{x_{n}\right\}$ defined by (1.3) to a common fixed point $p \in F=$ $\bigcap_{i=1}^{N} F\left(T_{i}\right)$.

Recently concerning the convergence problems of an implicit (or nonimplicit) iterative process to a common fixed point for a finite family of asymptotically nonexpansive mappings (or nonexpansive mappings) in Hilbert spaces or uniformly convex Banach spaces have been considered by several authors (see, e.g., Bauschke [1], Chang and Cho [3], Chang et al. [4], Chidume et al. [5], Goebel and Kirk [6], Górnicki [7], Halpern [8], Lions [10], Reich [12], Rhoades [13], Schu [14], Shioji and Takahashi [15], Tan and Xu $[16,17]$, Wittmann [18], Xu and Ori [19], and Zhou and Chang [20]).

In this paper, we introduce the following new implicit iterative sequence $\left\{x_{n}\right\}$ with errors:

$$
\begin{gathered}
x_{1}=\alpha_{1} x_{0}+\beta_{1} T_{1}\left(\hat{\alpha}_{1} x_{0}+\hat{\beta}_{1} T_{1} x_{1}+\hat{\gamma}_{1} v_{1}\right)+\gamma_{1} u_{1}, \\
x_{2}=\alpha_{2} x_{1}+\beta_{2} T_{2}\left(\hat{\alpha}_{2} x_{1}+\hat{\beta}_{2} T_{2} x_{2}+\hat{\gamma}_{2} v_{2}\right)+\gamma_{2} u_{2}, \\
\vdots \\
x_{N}=\alpha_{N} x_{N-1}+\beta_{N} T_{N}\left(\hat{\alpha}_{N} x_{N-1}+\hat{\beta}_{N} T_{N} x_{N}+\hat{\gamma}_{N} v_{N}\right)+\gamma_{N} u_{N}, \\
x_{N+1}=\alpha_{N+1} x_{N}+\beta_{N+1} T_{1}\left(\hat{\alpha}_{N+1} x_{N}+\hat{\beta}_{N+1} T_{1} x_{N+1}+\hat{\gamma}_{N+1} v_{N+1}\right)+\gamma_{N+1} u_{N+1}, \\
\vdots \\
x_{2 N+1}=\alpha_{2 N+1} x_{2 N}+\beta_{2 N+1} T_{1}\left(\hat{\alpha}_{2 N+1} x_{2 N}+\hat{\beta}_{2 N+1} T_{1} x_{2 N+1}+\hat{\gamma}_{2 N+1} v_{2 N+1}\right)+\gamma_{2 N+1} u_{2 N+1},
\end{gathered}
$$

for a finite family of nonexpansive mappings $\left\{T_{i}\right\}_{i=1}^{N}: K \rightarrow K$, where $\left\{\alpha_{n}\right\},\left\{\beta_{n}\right\},\left\{\gamma_{n}\right\}$, $\left\{\hat{\alpha}_{n}\right\},\left\{\hat{\beta}_{n}\right\}$, and $\left\{\hat{\gamma}_{n}\right\}$ are six sequences in $[0,1]$ satisfying $\alpha_{n}+\beta_{n}+\gamma_{n}=\hat{\alpha}_{n}+\hat{\beta}_{n}+\hat{\gamma}_{n}=1$ for all $n \geq 1, x_{0}$ is a given point in $K$, as well as $\left\{u_{n}\right\}$ and $\left\{v_{n}\right\}$ are two bounded sequences 
in $K$, which can be written in the following compact form:

$$
\begin{gathered}
x_{n}=\alpha_{n} x_{n-1}+\beta_{n} T_{n(\bmod N)} y_{n}+\gamma_{n} u_{n}, \\
y_{n}=\hat{\alpha}_{n} x_{n-1}+\hat{\beta}_{n} T_{n(\bmod N)} x_{n}+\hat{\gamma}_{n} v_{n}, \quad \forall n \geq 1 .
\end{gathered}
$$

Especially, if $\left\{T_{i}\right\}_{i=1}^{N}: K \rightarrow K$ are $N$ nonexpansive mappings, $\left\{\alpha_{n}\right\},\left\{\beta_{n}\right\},\left\{\gamma_{n}\right\}$ are three sequences in $[0,1]$, and $x_{0}$ is a given point in $K$, then the sequence $\left\{x_{n}\right\}$ defined by

$$
x_{n}=\alpha_{n} x_{n-1}+\beta_{n} T_{n(\bmod N)} x_{n-1}+\gamma_{n} u_{n}, \quad \forall n \geq 1
$$

is called the explicit iterative sequence for a finite family of nonexpansive mappings $\left\{T_{i}\right\}_{i=1}^{N}$.

The purpose of this paper is to study the weak and strong convergence of iterative sequence $\left\{x_{n}\right\}$ defined by (1.5) and (1.6) to a common fixed point for a finite family of nonexpansive mappings in Banach spaces. The results presented in this paper not only generalized and extend the corresponding results of Chang and Cho [3], Xu and Ori [19], and Zhou and Chang [20], but also in the case of $\gamma_{n}=\hat{\gamma}_{n}=0$ or $\hat{\beta}_{n}=\hat{\gamma}_{n}=0$ are also new.

In order to prove the main results of this paper, we need the following lemmas.

Lemma 1.2 [2]. Let $E$ be a uniformly convex Banach space, let $K$ be a nonempty closed convex subset of $E$, and let $T: K \rightarrow K$ be a nonexpansive mapping with $F(T) \neq \varnothing$. Then $I-T$ is semiclosed at zero, that is, for each sequence $\left\{x_{n}\right\}$ in $K$, if $\left\{x_{n}\right\}$ converges weakly to $q \in K$ and $\left\{(I-T) x_{n}\right\}$ converges strongly to 0 , then $(I-T) q=0$.

LEMMA 1.3 [17]. Let $\left\{a_{n}\right\}$ and $\left\{b_{n}\right\}$ be two nonnegative real sequences satisfying the following condition: $a_{n+1} \leq a_{n}+b_{n}$ for all $n \geq n_{0}$, where $n_{0}$ is some nonnegative integer. If $\sum_{n=0}^{\infty} b_{n}<\infty$, then $\lim _{n \rightarrow \infty} a_{n}$ exists. If in addition $\left\{a_{n}\right\}$ has a subsequence which converges strongly to zero, then $\lim _{n \rightarrow \infty} a_{n}=0$.

LeMma 1.4 [14]. Let E be a uniformly convex Banach space, let $b$ and $c$ be two constants with $0<b<c<1$. Suppose that $\left\{t_{n}\right\}$ is a sequence in $[b, c]$ and $\left\{x_{n}\right\}$ and $\left\{y_{n}\right\}$ are two sequence in E such that $\lim _{n \rightarrow \infty}\left\|t_{n} x_{n}+\left(1-t_{n}\right) y_{n}\right\|=d$, $\limsup _{n \rightarrow \infty}\left\|x_{n}\right\| \leq d$, and $\limsup _{n \rightarrow \infty}\left\|y_{n}\right\| \leq$ $d$ hold for some $d \geq 0$, then $\lim _{n \rightarrow \infty}\left\|x_{n}-y_{n}\right\|=0$.

Lemma 1.5. Let $E$ be a real Banach space, let $K$ be a nonempty closed convex subset of $E$, and let $\left\{T_{1}, T_{2}, \ldots, T_{N}\right\}: K \rightarrow K$ be $N$ nonexpansive mappings with $F=\bigcap_{i=1}^{N} F\left(T_{i}\right) \neq \varnothing$. Let $\left\{u_{n}\right\}$ and $\left\{v_{n}\right\}$ be two bounded sequences in $K$, and let $\left\{\alpha_{n}\right\},\left\{\beta_{n}\right\},\left\{\gamma_{n}\right\},\left\{\hat{\alpha}_{n}\right\},\left\{\hat{\beta}_{n}\right\}$, and $\left\{\hat{\gamma}_{n}\right\}$ be six sequences in $[0,1]$ satisfying the following conditions:

(i) $\alpha_{n}+\beta_{n}+\gamma_{n}=\hat{\alpha}_{n}+\hat{\beta}_{n}+\hat{\gamma}_{n}=1$, for all $n \geq 1$;

(ii) $\tau=\sup \left\{\beta_{n}: n \geq 1\right\}<1$;

(iii) $\sum_{n=1}^{\infty} \gamma_{n}<\infty, \sum_{n=1}^{\infty} \hat{\gamma}_{n}<\infty$.

If $\left\{x_{n}\right\}$ is the implicit iterative sequence defined by (1.5), then for each $p \in F=\bigcap_{i=1}^{N} F\left(T_{i}\right)$ the limit $\lim _{n \rightarrow \infty}\left\|x_{n}-p\right\|$ exists. 
4 A new composite implicit iterative process

Proof. Since $F=\bigcap_{n=1}^{N} F\left(T_{i}\right) \neq \varnothing$, for any given $p \in F$, it follows from (1.5) that

$$
\begin{aligned}
\left\|x_{n}-p\right\| & =\left\|\left(1-\beta_{n}-\gamma_{n}\right) x_{n-1}+\beta_{n} T_{n(\bmod N)} y_{n}+\gamma_{n} u_{n}-p\right\| \\
& \leq\left(1-\beta_{n}-\gamma_{n}\right)\left\|x_{n-1}-p\right\|+\beta_{n}\left\|T_{n(\bmod N)} y_{n}-p\right\|+\gamma_{n}\left\|u_{n}-p\right\| \\
& =\left(1-\beta_{n}-\gamma_{n}\right)\left\|x_{n-1}-p\right\|+\beta_{n}\left\|T_{n(\bmod N)} y_{n}-T_{n(\bmod N)} p\right\|+\gamma_{n}\left\|u_{n}-p\right\| \\
& \leq\left(1-\beta_{n}\right)\left\|x_{n-1}-p\right\|+\beta_{n}\left\|y_{n}-p\right\|+\gamma_{n}\left\|u_{n}-p\right\| .
\end{aligned}
$$

Again it follows from (1.5) that

$$
\begin{aligned}
\left\|y_{n}-p\right\| & =\left\|\left(1-\hat{\beta}_{n}-\hat{\gamma}_{n}\right) x_{n-1}+\hat{\beta}_{n} T_{n(\bmod N)} x_{n}+\hat{\gamma}_{n} v_{n}-p\right\| \\
& \leq\left(1-\hat{\beta}_{n}-\hat{\gamma}_{n}\right)\left\|x_{n-1}-p\right\|+\hat{\beta}_{n}\left\|T_{n(\bmod N)} x_{n}-p\right\|+\hat{\gamma}_{n}\left\|v_{n}-p\right\| \\
& =\left(1-\hat{\beta}_{n}-\hat{\gamma}_{n}\right)\left\|x_{n-1}-p\right\|+\hat{\beta}_{n}\left\|T_{n(\bmod N)} x_{n}-T_{n(\bmod N)}\right\|+\hat{\gamma}_{n}\left\|v_{n}-p\right\| \\
& \leq\left(1-\hat{\beta}_{n}\right)\left\|x_{n-1}-p\right\|+\hat{\beta}_{n}\left\|x_{n}-p\right\|+\hat{\gamma}_{n}\left\|v_{n}-p\right\| .
\end{aligned}
$$

Substituting (1.8) into (1.7), we obtain that

$$
\begin{aligned}
\left\|x_{n}-p\right\| \leq & \left(1-\beta_{n} \hat{\beta}_{n}\right)\left\|x_{n-1}-p\right\|+\beta_{n} \hat{\beta}_{n}\left\|x_{n}-p\right\| \\
& +\beta_{n} \hat{\gamma}_{n}\left\|v_{n}-p\right\|+\gamma_{n}\left\|u_{n}-p\right\| .
\end{aligned}
$$

Simplifying we have

$$
\left(1-\beta_{n} \hat{\beta}_{n}\right)\left\|x_{n}-p\right\| \leq\left(1-\beta_{n} \hat{\beta}_{n}\right)\left\|x_{n-1}-p\right\|+\sigma_{n},
$$

where $\sigma_{n}=\beta_{n} \hat{\gamma}_{n}\left\|v_{n}-p\right\|+\gamma_{n}\left\|u_{n}-p\right\|$. By condition (iii) and the boundedness of the sequences $\left\{\beta_{n}\right\},\left\{\left\|u_{n}-p\right\|\right\}$, and $\left\{\left\|v_{n}-p\right\|\right\}$, we have $\sum_{n=1}^{\infty} \sigma_{n}<\infty$. From condition (ii) we know that

$$
\beta_{n} \hat{\beta}_{n} \leq \beta_{n} \leq \tau<1 \text { and so } 1-\beta_{n} \hat{\beta}_{n} \geq 1-\tau>0 ;
$$

hence, from (1.10) we have

$$
\left\|x_{n}-p\right\| \leq\left\|x_{n-1}-p\right\|+\frac{\sigma_{n}}{1-\tau}=\left\|x_{n-1}-p\right\|+b_{n},
$$

where $b_{n}=\sigma_{n} /(1-\tau)$ with $\sum_{i=1}^{\infty} b_{n}<\infty$.

Taking $a_{n}=\left\|x_{n-1}-p\right\|$ in inequality (1.12), we have $a_{n+1} \leq a_{n}+b_{n}$, for all $n \geq 1$, and satisfied all conditions in Lemma 1.3. Therefore the $\operatorname{limit}_{n \rightarrow \infty}\left\|\lim _{n}-p\right\|$ exists. This completes the proof of Lemma 1.5.

\section{Main results}

We are now in a position to prove our main results in this paper. 
Theorem 2.1. Let $E$ be a real Banach space, let $K$ be a nonempty closed convex subset of $E$, and let $\left\{T_{1}, T_{2}, \ldots, T_{N}\right\}: K \rightarrow K$ be $N$ nonexpansive mappings with $F=\bigcap_{i=1}^{N} F\left(T_{i}\right) \neq \varnothing$ (the set of common fixed points of $\left\{T_{1}, T_{2}, \ldots, T_{N}\right\}$ ). Let $\left\{u_{n}\right\}$ and $\left\{v_{n}\right\}$ be two bounded sequences in $K$, and let $\left\{\alpha_{n}\right\},\left\{\beta_{n}\right\},\left\{\gamma_{n}\right\},\left\{\hat{\alpha}_{n}\right\},\left\{\hat{\beta}_{n}\right\}$, and $\left\{\hat{\gamma}_{n}\right\}$ be six sequences in $[0,1]$ satisfying the following conditions:

(i) $\alpha_{n}+\beta_{n}+\gamma_{n}=\hat{\alpha}_{n}+\hat{\beta}_{n}+\hat{\gamma}_{n}=1$, for all $n \geq 1$;

(ii) $\tau=\sup \left\{\beta_{n}: n \geq 1\right\}<1$;

(iii) $\sum_{n=1}^{\infty} \gamma_{n}<\infty, \sum_{n=1}^{\infty} \hat{\gamma}_{n}<\infty$.

Then the implicit iterative sequence $\left\{x_{n}\right\}$ defined by (1.5) converges strongly to a common fixed point $p \in F=\bigcap_{i=1}^{N} F\left(T_{i}\right)$ if and only if

$$
\liminf _{n \rightarrow \infty} d\left(x_{n}, F\right)=0 .
$$

Proof. The necessity of condition (2.1) is obvious.

Next we prove the sufficiency of Theorem 2.1. For any given $p \in F$, it follows from (1.12) in Lemma 1.5 that

$$
\left\|x_{n}-p\right\| \leq\left\|x_{n-1}-p\right\|+b_{n} \quad \forall n \geq 1
$$

where $b_{n}=\sigma_{n} /(1-\tau)$ with $\sum_{n=1}^{\infty} b_{n}<\infty$. Hence, we have

$$
d\left(x_{n}, F\right) \leq d\left(x_{n-1}, F\right)+b_{n} \quad \forall n \geq 1 .
$$

It follows from (2.3) and Lemma 1.3 that the $\operatorname{limit}_{n \rightarrow \infty} d\left(x_{n}, F\right)$ exists. By condition (2.1), we have $\lim _{n \rightarrow \infty} d\left(x_{n}, F\right)=0$.

Next we prove that the sequence $\left\{x_{n}\right\}$ is a Cauchy sequence in $K$. In fact, for any positive integers $m$ and $n$, from (2.2), it follows that

$$
\begin{aligned}
\left\|x_{n+m}-p\right\| & \leq\left\|x_{n+m-1}-p\right\|+b_{n+m} \leq\left\|x_{n+m-2}-p\right\|+b_{n+m-1}+b_{n+m} \\
& \leq \cdots \leq\left\|x_{n}-p\right\|+\sum_{i=n+1}^{n+m} b_{i} \leq\left\|x_{n}-p\right\|+\sum_{i=n+1}^{\infty} b_{i} .
\end{aligned}
$$

Since $\lim _{n \rightarrow \infty} d\left(x_{n}, F\right)=0$ and $\sum_{n=1}^{\infty} b_{n}<\infty$, for any given $\epsilon>0$, there exists a positive integer $n_{0}$ such that $d\left(x_{n}, F\right)<\epsilon / 8, \sum_{i=n+1}^{\infty} b_{i}<\epsilon / 2$, for all $n \geq n_{0}$. Therefore there exists $p_{1} \in F$ such that $\left\|x_{n}-p_{1}\right\|<\epsilon / 4$, for all $n \geq n_{0}$. Consequently, for any $n \geq n_{0}$ and for all $m \geq 1$, from (2.4), we have

$$
\begin{aligned}
\left\|x_{n+m}-x_{n}\right\| & \leq\left\|x_{n+m}-p_{1}\right\|+\left\|x_{n}-p_{1}\right\| \\
& \leq 2\left\|x_{n}-p_{1}\right\|+\sum_{i=n+1}^{\infty} b_{i}<2 \cdot \frac{\epsilon}{4}+\frac{\epsilon}{2}=\epsilon .
\end{aligned}
$$

This implies that $\left\{x_{n}\right\}$ is a Cauchy sequence in $K$. By the completeness of $K$, we can assume that $\lim _{n \rightarrow \infty} x_{n}=x^{*} \in K$. Moreover, since the set of fixed points of a nonexpansive mapping is closed, so is $F$; thus $x^{*} \in F$ from $\lim _{n \rightarrow \infty} d\left(x_{n}, F\right)=0$, that is, $x^{*}$ is a common fixed point of $T_{1}, T_{2}, \ldots, T_{N}$. This completes the proof of Theorem 2.1. 
Theorem 2.2. Let $E$ be a real Banach space, let $K$ be a nonempty closed convex subset of $E$, and let $\left\{T_{1}, T_{2}, \ldots, T_{N}\right\}: K \rightarrow K$ be $N$ nonexpansive mappings with $F=\bigcap_{i=1}^{N} F\left(T_{i}\right) \neq \varnothing$ (the set of common fixed points of $\left\{T_{1}, T_{2}, \ldots, T_{N}\right\}$ ). Let $\left\{u_{n}\right\}$ be a bounded sequence in $K$, and let $\left\{\alpha_{n}\right\},\left\{\beta_{n}\right\}$, and $\left\{\gamma_{n}\right\}$ be three sequences in $[0,1]$ satisfying the following conditions:

(i) $\alpha_{n}+\beta_{n}+\gamma_{n}=1$, for all $n \geq 1$;

(ii) $\tau=\sup \left\{\beta_{n}: n \geq 1\right\}<1$;

(iii) $\sum_{n=1}^{\infty} \gamma_{n}<\infty$.

Then the explicit iterative sequence $\left\{x_{n}\right\}$ defined by (1.6) converges strongly to a common fixed point $p \in F=\bigcap_{i=1}^{N} F\left(T_{i}\right)$ if and only if $\liminf _{n \rightarrow \infty} d\left(x_{n}, F\right)=0$.

Proof. Taking $\hat{\beta}_{n}=\hat{\gamma}_{n}=0$, for all $n \geq 1$ in Theorem 2.1, then the conclusion of Theorem 2.2 can be obtained from Theorem 2.1 immediately. This completes the proof of Theorem 2.2.

Theorem 2.3. Let E be a real uniformly convex Banach space satisfying Opial condition, let $K$ be a nonempty closed convex subset of $E$, and let $\left\{T_{1}, T_{2}, \ldots, T_{N}\right\}: K \rightarrow K$ be $N$ nonexpansive mappings with $F=\bigcap_{i=1}^{N} F\left(T_{i}\right) \neq \varnothing$. Let $\left\{u_{n}\right\}$ and $\left\{v_{n}\right\}$ be two bounded sequences in $K$, and let $\left\{\alpha_{n}\right\},\left\{\beta_{n}\right\},\left\{\gamma_{n}\right\},\left\{\hat{\alpha}_{n}\right\},\left\{\hat{\beta}_{n}\right\}$, and $\left\{\hat{\gamma}_{n}\right\}$ be six sequences in $[0,1]$ satisfying the following conditions:

(i) $\alpha_{n}+\beta_{n}+\gamma_{n}=\hat{\alpha}_{n}+\hat{\beta}_{n}+\hat{\gamma}_{n}=1$, for all $n \geq 1$;

(ii) $0<\tau_{1}=\inf \left\{\beta_{n}: n \geq 1\right\} \leq \sup \left\{\beta_{n}: n \geq 1\right\}=\tau_{2}<1$;

(iii) $\hat{\beta}_{n} \rightarrow 0(n \rightarrow \infty)$;

(iv) $\sum_{n=1}^{\infty} \gamma_{n}<\infty, \sum_{n=1}^{\infty} \hat{\gamma}_{n}<\infty$.

Then the implicit iterative sequence $\left\{x_{n}\right\}$ defined by (1.5) converges weakly to a common fixed point of $\left\{T_{1}, T_{2}, \ldots, T_{N}\right\}$.

Proof. First, we prove that

$$
\lim _{n \rightarrow \infty}\left\|x_{n}-T_{n(\bmod N)+j} x_{n}\right\|=0, \quad \forall j=1,2, \ldots, N .
$$

Let $p \in F$. Put $d=\lim _{n \rightarrow \infty}\left\|x_{n}-p\right\|$. It follows from (1.5) that

$$
\begin{aligned}
\left\|x_{n}-p\right\|= & \|\left(1-\beta_{n}\right)\left[x_{n-1}-p+\gamma_{n}\left(u_{n}-x_{n-1}\right)\right] \\
& +\beta_{n}\left[T_{n(\bmod N)} y_{n}-p+\gamma_{n}\left(u_{n}-x_{n-1}\right)\right] \| \longrightarrow d, \quad n \longrightarrow \infty
\end{aligned}
$$

Again since $\lim _{n \rightarrow \infty}\left\|x_{n}-p\right\|$ exists, so $\left\{x_{n}\right\}$ is a bounded sequence in $K$. By virtue of condition (iv) and the boundedness of sequences $\left\{x_{n}\right\}$ and $\left\{u_{n}\right\}$ we have

$$
\begin{aligned}
& \limsup _{n \rightarrow \infty}\left\|x_{n-1}-p+\gamma_{n}\left(u_{n}-x_{n-1}\right)\right\| \\
& \quad \leq \limsup _{n \rightarrow \infty}\left\|x_{n-1}-p\right\|+\limsup _{n \rightarrow \infty} \gamma_{n}\left\|u_{n}-x_{n-1}\right\|=d, \quad p \in F .
\end{aligned}
$$


It follows from (1.8) and condition (iii) that

$$
\begin{aligned}
\limsup _{n \rightarrow \infty} & \left\|T_{n(\bmod N)} y_{n}-p+\gamma_{n}\left(u_{n}-x_{n-1}\right)\right\| \\
\quad \leq & \limsup _{n \rightarrow \infty}\left\|y_{n}-p\right\|+\limsup _{n \rightarrow \infty} \gamma_{n}\left\|u_{n}-x_{n-1}\right\| \\
\quad & \limsup _{n \rightarrow \infty}\left\|y_{n}-p\right\| \\
& \leq \limsup _{n \rightarrow \infty}\left\{\left(1-\hat{\beta}_{n}\right)\left\|x_{n-1}-p\right\|+\hat{\beta}_{n}\left\|x_{n}-p\right\|+\hat{\gamma}_{n}\left\|v_{n}-p\right\|\right\} \\
& \leq \limsup _{n \rightarrow \infty}\left(1-\hat{\beta}_{n}\right)\left\|x_{n-1}-p\right\|+\limsup _{n \rightarrow \infty} \hat{\beta}_{n}\left\|x_{n}-p\right\|+\limsup _{n \rightarrow \infty} \hat{\gamma}_{n}\left\|v_{n}-p\right\| \\
& =d, \quad p \in F .
\end{aligned}
$$

Therefore, from condition (ii), (2.7)-(2.9), and Lemma 1.4 we know that

$$
\lim _{n \rightarrow \infty}\left\|T_{n(\bmod N)} y_{n}-x_{n-1}\right\|=0 .
$$

From (1.5) and (2.10) we have

$$
\begin{aligned}
\left\|x_{n}-x_{n-1}\right\| & =\left\|\beta_{n}\left[T_{n(\bmod N)} y_{n}-x_{n-1}\right]+\gamma_{n}\left(u_{n}-x_{n-1}\right)\right\| \\
& \leq \beta_{n}\left\|T_{n(\bmod N)} y_{n}-x_{n-1}\right\|+\gamma_{n}\left\|u_{n}-x_{n-1}\right\| \longrightarrow 0, \quad n \longrightarrow \infty,
\end{aligned}
$$

which implies that

$$
\lim _{n \rightarrow \infty}\left\|x_{n}-x_{n-1}\right\|=0
$$

and so

$$
\lim _{n \rightarrow \infty}\left\|x_{n}-x_{n+j}\right\|=0 \quad \forall j=1,2, \ldots, N
$$

On the other hand, we have

$$
\begin{aligned}
\left\|x_{n}-T_{n(\bmod N)} x_{n}\right\| \leq & \left\|x_{n}-x_{n-1}\right\|+\left\|x_{n-1}-T_{n(\bmod N)} y_{n}\right\| \\
& +\left\|T_{n(\bmod N)} y_{n}-T_{n(\bmod N)} x_{n}\right\| .
\end{aligned}
$$

Now, we consider the third term on the right-hand side of (2.14). From (1.5) we have

$$
\begin{aligned}
& \left\|T_{n(\bmod N)} y_{n}-T_{n(\bmod N)} x_{n}\right\| \\
& \quad \leq\left\|y_{n}-x_{n}\right\|=\left\|\hat{\alpha}_{n}\left(x_{n-1}-x_{n}\right)+\hat{\beta}_{n}\left(T_{n(\bmod N)} x_{n}-x_{n}\right)+\hat{\gamma}_{n}\left(v_{n}-x_{n}\right)\right\| \\
& \quad \leq \hat{\alpha}_{n}\left\|x_{n-1}-x_{n}\right\|+\hat{\beta}_{n}\left\|T_{n(\bmod N)} x_{n}-x_{n}\right\|+\hat{\gamma}_{n}\left\|v_{n}-x_{n}\right\| .
\end{aligned}
$$

Substituting (2.15) into (2.14), we obtain that

$$
\begin{aligned}
\left\|x_{n}-T_{n(\bmod N)} x_{n}\right\| \leq & \left(1+\hat{\alpha}_{n}\right)\left\|x_{n}-x_{n-1}\right\|+\left\|x_{n-1}-T_{n(\bmod N)} y_{n}\right\| \\
& +\hat{\beta}_{n}\left\|T_{n(\bmod N)} x_{n}-x_{n}\right\|+\hat{\gamma}_{n}\left\|v_{n}-x_{n}\right\| .
\end{aligned}
$$


Hence, by virtue of conditions (iii), (iv), (2.10), (2.12) and the boundedness of sequences $\left\{\left\|T_{n(\bmod N)} x_{n}-x_{n}\right\|\right\}$ and $\left\{\left\|v_{n}-x_{n}\right\|\right\}$ we have

$$
\lim _{n \rightarrow \infty}\left\|x_{n}-T_{n(\bmod N)} x_{n}\right\|=0
$$

Therefore, from (2.13) and (2.17), for any $j=1,2, \ldots, N$, we have

$$
\begin{aligned}
\left\|x_{n}-T_{n(\bmod N)+j} x_{n}\right\| \leq & \left\|x_{n}-x_{n+j}\right\|+\left\|x_{n+j}-T_{n(\bmod N)+j} x_{n+j}\right\| \\
& +\left\|T_{n(\bmod N)+j} x_{n+j}-T_{n(\bmod N)+j} x_{n}\right\| \\
\leq & 2|| x_{n}-x_{n+j}\|+\| x_{n+j}-T_{n(\bmod N)+j} x_{n+j} \| \longrightarrow 0, \quad n \longrightarrow \infty .
\end{aligned}
$$

That is, (2.6) holds.

Since $E$ is uniformly convex, every bounded subset of $E$ is weakly compact. Again since $\left\{x_{n}\right\}$ is a bounded sequence in $K$, there exists a subsequence $\left\{x_{n_{k}}\right\} \subset\left\{x_{n}\right\}$ such that $\left\{x_{n_{k}}\right\}$ converges weakly to $q \in K$.

Without loss of generality, we can assume that $n_{k}=i(\bmod N)$, where $i$ is some positive integer in $\{1,2, \ldots, N\}$. Otherwise, we can take a subsequence $\left\{x_{n_{k_{j}}}\right\} \subset\left\{x_{n_{k}}\right\}$ such that $n_{k_{j}}=i(\bmod N)$. For any $l \in\{1,2, \ldots, N\}$, there exists an integer $j \in\{1,2, \ldots, N\}$ such that $n_{k}+j=l(\bmod N)$. Hence, from $(2.18)$ we have

$$
\lim _{k \rightarrow \infty}\left\|x_{n_{k}}-T_{l} x_{n_{k}}\right\|=0, \quad l=1,2, \ldots, N
$$

By Lemma 1.2, we know that $q \in F\left(T_{l}\right)$. By the arbitrariness of $l \in\{1,2, \ldots, N\}$, we know that $q \in F=\bigcap_{j=1}^{N} F\left(T_{j}\right)$.

Finally, we prove that $\left\{x_{n}\right\}$ converges weakly to $q$. In fact, suppose the contrary, then there exists some subsequence $\left\{x_{n_{j}}\right\} \subset\left\{x_{n}\right\}$ such that $\left\{x_{n_{j}}\right\}$ converges weakly to $q_{1} \in K$ and $q_{1} \neq q$. Then by the same method as given above, we can also prove that $q_{1} \in F=$ $\bigcap_{j=1}^{N} F\left(T_{j}\right)$.

Taking $p=q$ and $p=q_{1}$ and by using the same method given in the proof of Lemma 1.5, we can prove that the following two limits exist and $\lim _{n \rightarrow \infty}\left\|x_{n}-q\right\|=d_{1}$ and $\lim _{n \rightarrow \infty}\left\|x_{n}-q_{1}\right\|=d_{2}$, where $d_{1}$ and $d_{2}$ are two nonnegative numbers. By virtue of the Opial condition of $E$, we have

$$
\begin{aligned}
d_{1} & =\limsup _{n_{k} \rightarrow \infty}\left\|x_{n_{k}}-q\right\|<\limsup _{n_{k} \rightarrow \infty}\left\|x_{n_{k}}-q_{1}\right\|=d_{2} \\
& =\limsup _{n_{j} \rightarrow \infty}\left\|x_{n_{j}}-q_{1}\right\|<\underset{n_{j} \rightarrow \infty}{\limsup }\left\|x_{n_{j}}-q\right\|=d_{1} .
\end{aligned}
$$

This is a contradiction. Hence $q_{1}=q$. This implies that $\left\{x_{n}\right\}$ converges weakly to $q$. This completes the proof of Theorem 2.3.

Theorem 2.4. Let E be a real uniformly convex Banach space satisfying Opial condition, let $K$ be a nonempty closed convex subset of $E$, and let $\left\{T_{1}, T_{2}, \ldots, T_{N}\right\}: K \rightarrow K$ be $N$ nonexpansive mappings with $F=\bigcap_{i=1}^{N} F\left(T_{i}\right) \neq \varnothing$. Let $\left\{u_{n}\right\}$ be a bounded sequence in $K$, and let 
$\left\{\alpha_{n}\right\},\left\{\beta_{n}\right\}$, and $\left\{\gamma_{n}\right\}$ be three sequences in $[0,1]$ satisfying the following conditions:

(i) $\alpha_{n}+\beta_{n}+\gamma_{n}=1, \forall n \geq 1$;

(ii) $0<\tau_{1}=\inf \left\{\beta_{n}: n \geq 1\right\} \leq \sup \left\{\beta_{n}: n \geq 1\right\}=\tau_{2}<1$;

(iii) $\sum_{n=1}^{\infty} \gamma_{n}<\infty$.

Then the explicit iterative sequence $\left\{x_{n}\right\}$ defined by (1.6) converges weakly to a common fixed point of $\left\{T_{1}, T_{2}, \ldots, T_{N}\right\}$.

Proof. Taking $\hat{\beta}_{n}=\hat{\gamma}_{n}=0$, for all $n \geq 1$ in Theorem 2.3, then the conclusion of Theorem 2.4 can be obtained from Theorem 2.3 immediately. This completes the proof of Theorem 2.4 .

Theorem 2.5. Let $E$ be a real uniformly convex Banach space, let $K$ be a nonempty closed convex subset of $E$, and let $\left\{T_{1}, T_{2}, \ldots, T_{N}\right\}: K \rightarrow K$ be $N$ nonexpansive mappings with $F=$ $\bigcap_{i=1}^{N} F\left(T_{i}\right) \neq \varnothing$ and there exists an $T_{j}, 1 \leq j \leq N$, which is semicompact (without loss of generality, assume that $T_{1}$ is semicompact). Let $\left\{u_{n}\right\}$ and $\left\{v_{n}\right\}$ be two bounded sequences in $K$, and let $\left\{\alpha_{n}\right\},\left\{\beta_{n}\right\},\left\{\gamma_{n}\right\},\left\{\hat{\alpha}_{n}\right\},\left\{\hat{\beta}_{n}\right\}$, and $\left\{\hat{\gamma}_{n}\right\}$ be six sequences in $[0,1]$ satisfying the following conditions:

(i) $\alpha_{n}+\beta_{n}+\gamma_{n}=\hat{\alpha}_{n}+\hat{\beta}_{n}+\hat{\gamma}_{n}=1$, for all $n \geq 1$;

(ii) $0<\tau_{1}=\inf \left\{\beta_{n}: n \geq 1\right\} \leq \sup \left\{\beta_{n}: n \geq 1\right\}=\tau_{2}<1$;

(iii) $\hat{\beta}_{n} \rightarrow 0(n \rightarrow \infty)$;

(iv) $\sum_{n=1}^{\infty} \gamma_{n}<\infty, \sum_{n=1}^{\infty} \hat{\gamma}_{n}<\infty$.

Then the implicit iterative sequence $\left\{x_{n}\right\}$ defined by (1.5) converges strongly to a common fixed point of $\left\{T_{1}, T_{2}, \ldots, T_{N}\right\}$ in $K$.

Proof. For any given $p \in F=\bigcap_{i=1}^{N} F\left(T_{i}\right)$, by the same method as given in proving Lemma 1.5 and (2.19), we can prove that

$$
\lim _{n \rightarrow \infty}\left\|x_{n}-p\right\|=d
$$

where $d \geq 0$ is some nonnegative number, and

$$
\lim _{k \rightarrow \infty}\left\|x_{n_{k}}-T_{l} x_{n_{k}}\right\|=0, \quad l=1,2, \ldots, N
$$

Especially, we have

$$
\lim _{k \rightarrow \infty}\left\|x_{n_{k}}-T_{1} x_{n_{k}}\right\|=0
$$

By the assumption, $T_{1}$ is semicompact; therefore it follows from (2.23) that there exists a subsequence $\left\{x_{n_{k_{i}}}\right\} \subset\left\{x_{n_{k}}\right\}$ such that $x_{n_{k_{i}}} \rightarrow x^{*} \in K$. Hence from (2.22) we have that

$$
\left\|x^{*}-T_{l} x^{*}\right\|=\lim _{k_{i} \rightarrow \infty}\left\|x_{n_{k_{i}}}-T_{l} x_{n_{k_{i}}}\right\|=0 \quad \forall l=1,2, \ldots, N
$$

which implies that $x^{*} \in F=\bigcap_{i=1}^{N} F\left(T_{i}\right)$. Take $p=x^{*}$ in (2.21), similarly we can prove that $\lim _{n \rightarrow \infty}\left\|x_{n}-x^{*}\right\|=d_{1}$, where $d_{1} \geq 0$ is some nonnegative number. From $x_{n_{k_{i}}} \rightarrow x^{*}$ we know that $d_{1}=0$, that is, $x_{n} \rightarrow x^{*}$. This completes the proof of Theorem 2.5. 
Theorem 2.6. Let $E$ be a real uniformly convex Banach space, let $K$ be a nonempty closed convex subset of $E$, and let $\left\{T_{1}, T_{2}, \ldots, T_{N}\right\}: K \rightarrow K$ be $N$ nonexpansive mappings with $F=\bigcap_{i=1}^{N} F\left(T_{i}\right) \neq \varnothing$ and there exists an $T_{j}, 1 \leq j \leq N$, which is semicompact (without loss of generality, assume that $T_{1}$ is semicompact). Let $\left\{u_{n}\right\}$ be a bounded sequence in $K$, and let $\left\{\alpha_{n}\right\},\left\{\beta_{n}\right\}$, and $\left\{\gamma_{n}\right\}$ be three sequences in $[0,1]$ satisfying the following conditions:

(i) $\alpha_{n}+\beta_{n}+\gamma_{n}=1$, for all $n \geq 1$;

(ii) $0<\tau_{1}=\inf \left\{\beta_{n}: n \geq 1\right\} \leq \sup \left\{\beta_{n}: n \geq 1\right\}=\tau_{2}<1$;

(iii) $\sum_{n=1}^{\infty} \gamma_{n}<\infty$.

Then the explicit iterative sequence $\left\{x_{n}\right\}$ defined by (1.6) converges strongly to a common fixed point of $\left\{T_{1}, T_{2}, \ldots, T_{N}\right\}$ in $K$.

Proof. Taking $\hat{\beta}_{n}=\hat{\gamma}_{n}=0$, for all $n \geq 1$ in Theorem 2.5, then the conclusion of Theorem 2.6 can be obtained from Theorem 2.5 immediately. This completes the proof of Theorem 2.6.

Remark 2.7. Theorems 2.3-2.6 improve and extend the corresponding results in Chang and Cho [3, Theorem 3.1] and Zhou and Chang [20, Theorem 3], and the implicit iterative process $\left\{x_{n}\right\}$ defined by (1.3) is replaced by the more general implicit or explicit iterative process $\left\{x_{n}\right\}$ defined by (1.5) or (1.6).

Remark 2.8. Theorems 2.3-2.6 generalize and improve the main results of $\mathrm{Xu}$ and Ori [19] in the following aspects.

(1) The class of Hilbert spaces is extended to that of Banach spaces satisfying Opial's or semicompactness condition.

(2) The implicit iterative process $\left\{x_{n}\right\}$ defined by (1.3) is replaced by the more general implicit or explicit iterative process $\left\{x_{n}\right\}$ defined by (1.5) or (1.6).

Remark 2.9. The iterative algorithm used in this paper is different from those in $[1,8,10$, $14,18]$.

\section{Acknowledgments}

The present studies were supported by the Natural Science Foundation of Zhejiang Province (Y605191), the Natural Science Foundation of Heilongjiang Province (A0211), and the Scientific Research Foundation from Zhejiang Province Education Committee (20051897).

\section{References}

[1] H. H. Bauschke, The approximation of fixed points of compositions of nonexpansive mappings in Hilbert space, Journal of Mathematical Analysis and Applications 202 (1996), no. 1, 150-159.

[2] F. E. Browder, Nonlinear operators and nonlinear equations of evolution in Banach spaces, Nonlinear Functional Analysis (Proc. Sympos. Pure Math., Vol. 18, Part 2, Chicago, Ill., 1968), American Mathematical Society, Rhode Island, 1976, pp. 1-308.

[3] S.-S. Chang and Y. J. Cho, The implicit iterative processes for asymptotically nonexpansive mappings, Nonlinear Analysis and Applications: to V. Lakshmikantham on His 80th Birthday. Vol. 1, 2, Kluwer Academic, Dordrecht, 2003, pp. 369-382. 
[4] S.-S. Chang, Y. J. Cho, and H. Zhou, Demi-closed principle and weak convergence problems for asymptotically nonexpansive mappings, Journal of the Korean Mathematical Society 38 (2001), no. $6,1245-1260$.

[5] C. E. Chidume, H. Zegeye, and N. Shahzad, Convergence theorems for a common fixed point of a finite family of nonself nonexpansive mappings, Fixed Point Theory and Applications 2005 (2005), no. 2, 233-241.

[6] K. Goebel and W. A. Kirk, A fixed point theorem for asymptotically nonexpansive mappings, Proceedings of the American Mathematical Society 35 (1972), no. 1, 171-174.

[7] J. Górnicki, Weak convergence theorems for asymptotically nonexpansive mappings in uniformly convex Banach spaces, Commentationes Mathematicae Universitatis Carolinae 30 (1989), no. 2, 249-252.

[8] B. Halpern, Fixed points of nonexpanding maps, Bulletin of the American Mathematical Society 73 (1967), 957-961.

[9] E. Lami Dozo, Multivalued nonexpansive mappings and Opial's condition, Proceedings of the American Mathematical Society 38 (1973), no. 2, 286-292.

[10] P.-L. Lions, Approximation de points fixes de contractions, Comptes Rendus de l'Académie des Sciences de Paris Série A 284 (1977), no. 21, 1357-1359.

[11] Z. Opial, Weak convergence of the sequence of successive approximations for nonexpansive mappings, Bulletin of the American Mathematical Society 73 (1967), 591-597.

[12] S. Reich, Strong convergence theorems for resolvents of accretive operators in Banach spaces, Journal of Mathematical Analysis and Applications 75 (1980), no. 1, 287-292.

[13] B. E. Rhoades, Quadratic optimization of fixed points for a family of nonexpansive mappings in Hilbert space, Fixed Point Theory and Applications 2004 (2004), no. 2, 135-147.

[14] J. Schu, Weak and strong convergence to fixed points of asymptotically nonexpansive mappings, Bulletin of the Australian Mathematical Society 43 (1991), no. 1, 153-159.

[15] N. Shioji and W. Takahashi, Strong convergence theorems for asymptotically nonexpansive semigroups in Hilbert spaces, Nonlinear Analysis. Theory, Methods \& Applications 34 (1998), no. 1, $87-99$.

[16] K.-K. Tan and H.-K. Xu, The nonlinear ergodic theorem for asymptotically nonexpansive mappings in Banach spaces, Proceedings of the American Mathematical Society 114 (1992), no. 2, 399404.

[17] __ Approximating fixed points of nonexpansive mappings by the Ishikawa iteration process, Journal of Mathematical Analysis and Applications 178 (1993), no. 2, 301-308.

[18] R. Wittmann, Approximation of fixed points of nonexpansive mappings, Archiv der Mathematik 58 (1992), no. 5, 486-491.

[19] H.-K. Xu and R. G. Ori, An implicit iteration process for nonexpansive mappings, Numerical Functional Analysis and Optimization 22 (2001), no. 5-6, 767-773.

[20] Y. Zhou and S.-S. Chang, Convergence of implicit iteration process for a finite family of asymptotically nonexpansive mappings in Banach spaces, Numerical Functional Analysis and Optimization 23 (2002), no. 7-8, 911-921.

Feng Gu: Department of Mathematics, Institute of Applied Mathematics, Hangzhou Teacher's College, Hangzhou, Zhejiang 310036, China E-mail address: gufeng99@sohu.com

Jing Lu: Department of Mathematics, Institute of Applied Mathematics, Hangzhou Teacher's College, Hangzhou, Zhejiang 310036, China

E-mail address: wllujing@sina.com 